\title{
CORRECTION
}

View Article Online

View Journal | View Issue

\section{Correction: A computational study of tri-s- triazine-based molecules as ambipolar host materials for phosphorescent blue emitters: effective geometric and electronic tuning}

Cite this: J. Mater. Chem. C, 2015, 3, 6094

\author{
Jing $\mathrm{Li}^{\mathrm{a}}{ }^{2}$ Zhaomin Nie, ${ }^{a} \mathrm{Hai} \mathrm{Li},{ }^{\star b}$ Yiming Peng, ${ }^{a}$ Ziyuan Wang, ${ }^{a}$ Zhirui Mai ${ }^{\mathrm{a}}$ and \\ Wenxu Zheng*a
}

DOI: $10.1039 / c 5 t c 90088 c$

Correction for 'A computational study of tri-s-triazine-based molecules as ambipolar host materials for phosphorescent blue emitters: effective geometric and electronic tuning' by Jing Li et al., J. Mater.

www.rsc.org/MaterialsC

Chem. C, 2015, 3, 4859.

There were errors in the structures depicted in Schemes 1 and 2. These have been revised and the correct versions of Schemes 1 and 2 are:<smiles>[R]C1=NC2=NC([R])=NC3=NC(n4c5c([R])cc([R])cc5c5cc([R3])cc([R])c54)=NC(=N1)N23</smiles>

Scheme 1 The structure of designed tri-s-triazine derivatives $\left(\mathrm{R}=\mathrm{F}, \mathrm{Cl}, \mathrm{Br}, \mathrm{CN}, \mathrm{NO}_{2}, \mathrm{COOH}, \mathrm{NH}_{2}, \mathrm{OH}, \mathrm{OPh}\right.$, SPh, methyl, ethyl, propyl, i-propyl, butyl, i-butyl and t-butyl).

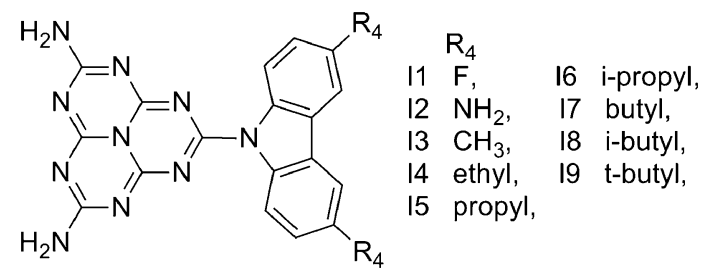

Scheme 2 Sketch map of the structures of series I.

The Royal Society of Chemistry apologises for these errors and any consequent inconvenience to authors and readers.

${ }^{a}$ College of Materials and Energy, South China Agricultural University, Guangzhou 510642, China. E-mail: wzheng@scau.edu.cn; Fax: +86 2085285026; Tel: +862085280325

${ }^{b}$ College of electronic engineering, South China Agricultural University, Guangzhou 510642, China. E-mail: lee.361@163.com; Fax: +86 2085285026; Tel: +86 2085280324 